(25) E. B. Carew, I. M. Asher, and H. E. Stanley, Science, 188, 933 (1975); I. M. Asher, E. B. Carew, and H. E. Stanley, "Physiology of Smooth Muscle", E. Bulbring, Ed., Raven Press, New York, N.Y., 1976.

(26) K. J. Rothschild and H. E. Stanley, Science, 185, 616 (1974); I. M. Asher, G. D. J. Phillies, and H. E. Stanley, Blochem. Biophys. Res. Commun., 61, 1356 (1974); G. D. J. Phillies, I. M. Asher, and H. E. Stanley, Sclence, 188, $1027(1975)$.

(27) G. D. J. Phillies, I. M. Asher, and H. E. Stanley, Blopolymers, 14, 2311 (1975); I. M. Asher, G. D. J. Phillies, B. J. Kim, and H. E. Stanley, ibid., 16, $157(1977)$

(28) C. H. Perry, D. K. Agrawal, E. Anastassakis, R. P. Lowndes, and N. E. Tornberg, Geochim. Cosmochim. Acta, 3, 3077 (1972).

(29) B. Fanconi, E. Small, and W. L. Peticolas, Blopolymers, 10, 1277 (1971).

(30) T. Miyazawa, T. Shimanouchi, and S. Mizushima, J. Chem. Phys., 29, 611 (1958).

(31) V. T. Ivanov, G. A. Kogan, V. M. Tulchinsky, A. V. Miroshnikov, I. I. Mikhalyova, A. V. Evstratov, A. A. Zenkin, P. V. Kostetsky, Yu. A. Ovchinnikov, and B. V. Lokshin, FEBS Lett., 30, 199 (1973).

(32) E. W. Small, B. Falconi, and W. L. Peticolas, J. Chem. Phys., 52, 4369 (1970).

(33) J. L. Koenig and P. Sutton, Blopolymers, 10, 89 (1971)

(34) H. Tadokoro, M. Kobayashi, H. Yoshidome, K. Tai, and D. Makino, J. Chem. Phys., 49, 3359 (1968)

(35) A. R. Katrizky, J. M. Lagowski, and J. A. T. Beard, Spectrochim. Acta, 16, $954(1960)$.

(36) R. Richards and H. Thompson, J. Chem. Soc., 1248 (1947)

(37) Yu. A. Ovchinnikov, FEBS Lett., 44, 1 (1974)

(38) T. J. Yu, J. L. Lippert, and W. L. Peticolas, Blopolymers, 12, 2161 (1973); J. L. Lippert, private communication.

(39) P. C. Painter and J. L. Koenig, Biopolymers, 15, 241 (1976)

(40) K. J. Rothschlld and H. E. Stantey, Amer. J. Clin. Pathol., 63, 695 (1975); H. E. Stanley, I. M. Asher, K. J. Rothschild, G. D. J. Phillies, E. B. Carew, R. D. Bansil, and I. A. Michaels, "Peptides: Chemistry, Structure and Blology", R. Walter and J. Meirhhofer, Ed., Ann Arbor Science, Ann Arbor, Mich., 1975, pp 227-245.

\title{
Raman Spectroscopy of Uncomplexed Valinomycin. 2. Nonpolar and Polar Solution
}

\author{
Kenneth J. Rothschild, ${ }^{* 1 b}$ Irvin M. Asher, ${ }^{1 b}$ H. Eugene Stanley, ${ }^{1 a}$ and Evangelos \\ Anastassakis $^{1 \mathrm{c}}$ \\ Contribution from the Harvard-MIT Program in Health Sciences and Technology, \\ Massachusetts Institute of Technology, Cambridge, Massachusetts 02139. \\ Received March 26, 1976
}

\begin{abstract}
The molecular conformations of uncomplexed valinomycin in $\mathrm{CCl}_{4}, \mathrm{CS}_{2}, \mathrm{CH}_{2} \mathrm{Cl}_{2}, \mathrm{CHCl}_{3}, \mathrm{CH}_{3} \mathrm{OH}, \mathrm{C}_{2} \mathrm{H}_{5} \mathrm{OH}$ $\mathrm{C}_{3} \mathrm{H}_{7} \mathrm{Cl}$, $p$-dioxane $\left(\mathrm{C}_{4} \mathrm{H}_{8} \mathrm{O}_{2}\right)$, and dioxane $/ \mathrm{D}_{2} \mathrm{O}$ have been studied using laser Raman spectroscopy. The stretching frequencies of the ester and amide carbonyl groups are found to be affected by both the polarity of the solvent and its ability to form hydrogen bonds. Results in nonpolar solvents are consistent with the presence of hydrogen bonding ester carbonyl groups, reopening the question of whether the conformation found in valinomycin recrystallized from $n$-octane can exist in nonpolar solution. In polar solvents, a conformation is detected that contains fewer hydrogen bonds. As the dielectric constant of the solvent increases, the stretching frequency of the amide carbonyl groups increases (perhaps reflecting a reduction of intramolecular hydrogen bonding), while the stretching frequency of the ester carbonyl groups decreases.
\end{abstract}

The macrocyclic dodecadepsipeptide valinomycin (hereafter abbreviated VM; Figure 1a) was among the first ionspecific antibiotics to be used as a model of ionic transport in biological membranes. ${ }^{2-4}$ Although the three-dimensional structure of crystals can often be obtained with $\mathrm{x}$-ray or neutron diffraction, these techniques cannot provide information about whether conformations found in the solid state persist in solution. In contrast, Raman spectroscopy can be applied to both solids and liquids, permitting one to compare structural characteristics of molecules in a variety of environments. Raman spectroscopic investigations of the molecular conformations of VM in the solid state have recently been reported, ${ }^{5}$ and in this work we report studies of VM in a variety of solvents. These studies, which include deuteration of the NH groups, reveal new information about the dependence of VM conformation on environment.

$\mathrm{X}$-ray methods have been used to reveal ${ }^{6.7}$ the complete structure of one form of uncomplexed VM; all six NH groups are intramolecularly hydrogen bonded, four to amide $\mathrm{C}=\mathrm{O}$ groups and two to ester $\mathrm{C}=\mathrm{O}$ groups (conformation $\mathrm{D}$, Figure 1b). Structural similarities between crystalline uncomplexed VM and the VM-K $\mathrm{K}^{+}$complex have led to the suggestion ${ }^{6}$ that this form may be involved in ion complexation at the membrane-water interface. However, nuclear magnetic resonance (NMR), infrared absorption (IR), and optical rotatory dispersion (ORD) studies ${ }^{4,8-11}$ reveal no evidence of conformation

* Address correspondence to this author at the Department of Physics, Boston University, 111 Cummington St., Boston, Mass. 02215.
$\mathrm{D}$ in solution. One question we address is whether or not there is Raman spectroscopic evidence that conformation D persists in solution.

A mixture of several VM conformations exists in solution. ${ }^{4,8-11}$ It is believed that the predominant conformation of VM in nonpolar solvents contains six hydrogen-bonded amide $\mathrm{C}=\mathrm{O}$ groups and six unbonded ester $\mathrm{C}=\mathrm{O}$ groups (conformation A, Figure $1 \mathrm{c}$ ), while the predominant conformation in polar solvents is believed to contain only three hydrogen bonded amide $\mathrm{C}=\mathrm{O}$ groups (conformation $\mathrm{B}$, Figure 1d). These conclusions are based primarily on NMR data, ${ }^{9}$ which indicate a threefold equivalence of $\mathrm{L}$ - and D-valine protons. Conformation D lacks this symmetry; however, Patel and Tonelli ${ }^{9}$ have pointed out that asymmetric structures could exist in solution if they were in "rapid" equilibrium with each other (rapid on an NMR time scale) thereby appearing to be symmetric in NMR measurements.

The Raman spectra of VM recrystallized from $n$-octane (known ${ }^{7}$ to be in conformation D) exhibit a hydrogen-bonded ester $\mathrm{C}=\mathrm{O}$ group mode near $1742 \mathrm{~cm}^{-1}, 25 \mathrm{~cm}^{-1}$ lower in frequency than the corresponding mode of the free $\mathrm{C}=\mathrm{O}$ groups. ${ }^{5}$ The discovery of a similar downshift (or splitting) in solution would support the presence of hydrogen bonded ester $\mathrm{C}=\mathrm{O}$ groups (and thus conformation $\mathrm{D}$ ) in such environments.

\section{Materials and Methods}

Valinomycin (VM) was obtained from Calbiochem (San Diego, Calif.) and Sigma Chemicals (St. Louis, Mo.) and was used without 


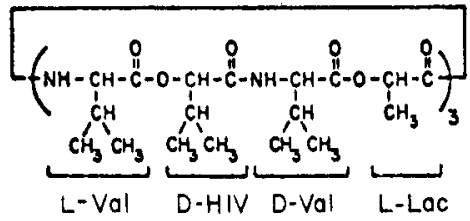

a) Valinomycin (VM)

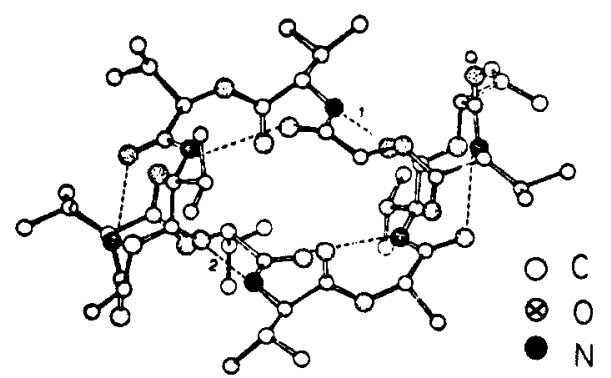

b) Conformation D

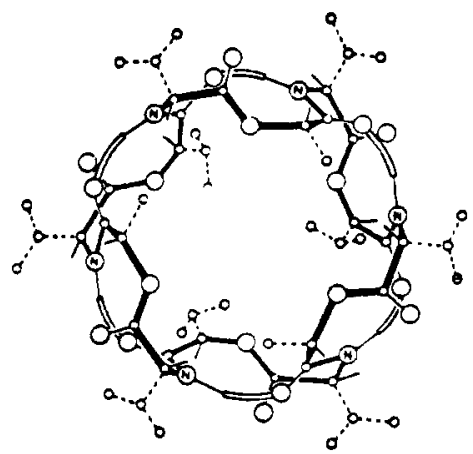

c) Conformation $\mathrm{A}$



\section{d) Conformation $B$}

Figure 1. (a) Primary structure of valinomycin. Here L-Val denotes Lvaline; $\mathrm{D}-\mathrm{HIV}$ denotes $\mathrm{D}$-hydroxyisovaleric acid; $\mathrm{D}-\mathrm{Val}$, denotes D-valine: and L-Lac denotes L-lactic acid. (b) Structure of uncomplexed valinomycin crystallized from $n$-octane (from ref 6 ). (c) Predicted predominant conformation of valinomycin in nonpolar solvents (from ref 4). (d) Predicted predominant conformation of valinomycin in polar solvents (from ref 4).

further purification. Solutions $(0.02-0.5 \mathrm{M})$ were injected into $1.0-\mathrm{mm}$ i.d. capillaries and centrifuged for $5 \mathrm{~min}$ to eliminate dust and dissolved air. Deuteration was accomplished directly in the capillary tube by exchange across a $D_{2} \mathrm{O} / \mathrm{CCl}_{4}$ interface; Raman spectra were recorded at regular intervals over a 24 -hr period and subsequently checked over periods of several months.

Raman spectra were measured using a Spex Ramalog 4 system and a Spectra-Physics Model 164-03 $\mathrm{Ar}^{+}$laser (488.0- and 514.5-nm excitations). The incident power level was typically $150-200 \mathrm{~mW}$, resolution $3 \mathrm{~cm}^{-1}$, and scanning speed $3-30 \mathrm{~cm}^{-1} / \mathrm{min}$. For polar-

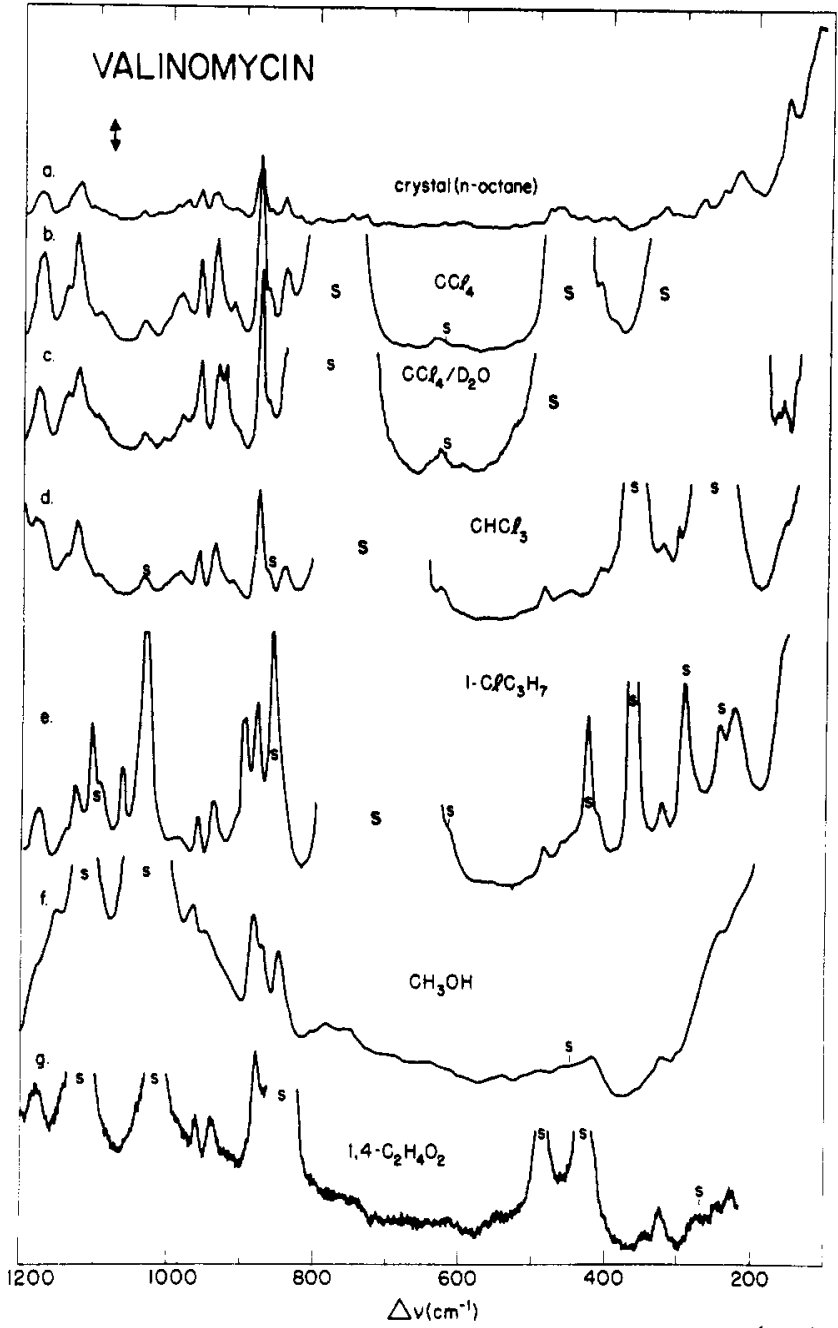

Figure 2. Comparison of the Raman spectra in the $100-1200-\mathrm{cm}^{-1}$ region for: (a) crystalline valinomycin grown from $n$-octane and solutions of valinomycin dissolved in (b) $\mathrm{CCl}_{4}$, (c) $\mathrm{CCl}_{4}$ with $\mathrm{D}_{2} \mathrm{O}$ in contact as a second phase, (d) $\mathrm{CHCl}_{3}$, (e) $1-\mathrm{ClC}_{3} \mathrm{H}_{7}$, (f) $\mathrm{CH}_{3} \mathrm{OH}$ and, (g) 1,4-dioxane (p-dioxane). Spectra were recorded with incident powers, $20-200 \mathrm{~mW}$, exciting frequencies $457.9,488.0,514.5 \mathrm{~nm}$, spectral resolution $3 \mathrm{~cm}^{-1}$, scanning speed $0.1-0.5 \mathrm{~cm}^{-1} / \mathrm{s}$. Vertical arrow represents 300 counts $/ \mathrm{s}$ in (b-g) and 1000 counts $/ \mathrm{s}$ in (a). No analyzer in scattered beam; incident light polarized perpendicular to the scattering plane. $S$ denotes solvent peak.

ization measurements, an analyzer was placed in front of the spectrometer; the incident laser light was polarized perpendicular to the scattering plane. Further details of the Raman spectroscopy system are presented in ref 5 .

\section{Results}

(A) $\mathrm{CCl}_{4}$ (Nonpolar) Solution. We begin by comparing the Raman spectrum of VM powder recrystallized from $n$-octane (Figures $2 \mathrm{a}$ and $3 \mathrm{a}$ ) with that of $\mathrm{VM}$ dissolved in $\mathrm{CCl}_{4}$ (Figures $2 \mathrm{~b}$ and $3 \mathrm{~b}$ ). Although some spectral regions (denoted by $\mathrm{S}$ ) are obscured by solvent peaks, most regions of the crystalline and solution spectra are similar. This is not surprising since many peaks are due to residue vibrations which should be relatively insensitive to conformational change. However, spectral changes are observed in the conformationally sensitive 1600-1800 $\mathrm{cm}^{-1}\left(\mathrm{C}=\mathrm{O}\right.$ stretch), 1220-1320 $\mathrm{cm}^{-1}$ (amide III), and $3300-3450 \mathrm{~cm}^{-1}$ (NH stretch) spectral regions. In addition, the 981 - and $1020-\mathrm{cm}^{-1}$ peaks of crystalline VM shift somewhat in $\mathrm{CCl}_{4}$ solution.

(1) The $\mathrm{C}=0$ Stretch Region $\left(1600-1800 \mathrm{~cm}^{-1}\right)$. Prominent amide and ester $\mathrm{C}=\mathrm{O}$ stretch vibrations occur in the $1600-$ $1700-\mathrm{cm}^{-1}$ and the $1700-1800-\mathrm{cm}^{-1}$ regions, respectively. ${ }^{5}$ An analysis of these regions of VM powder (Figure $4 \mathrm{a}$ ) and 


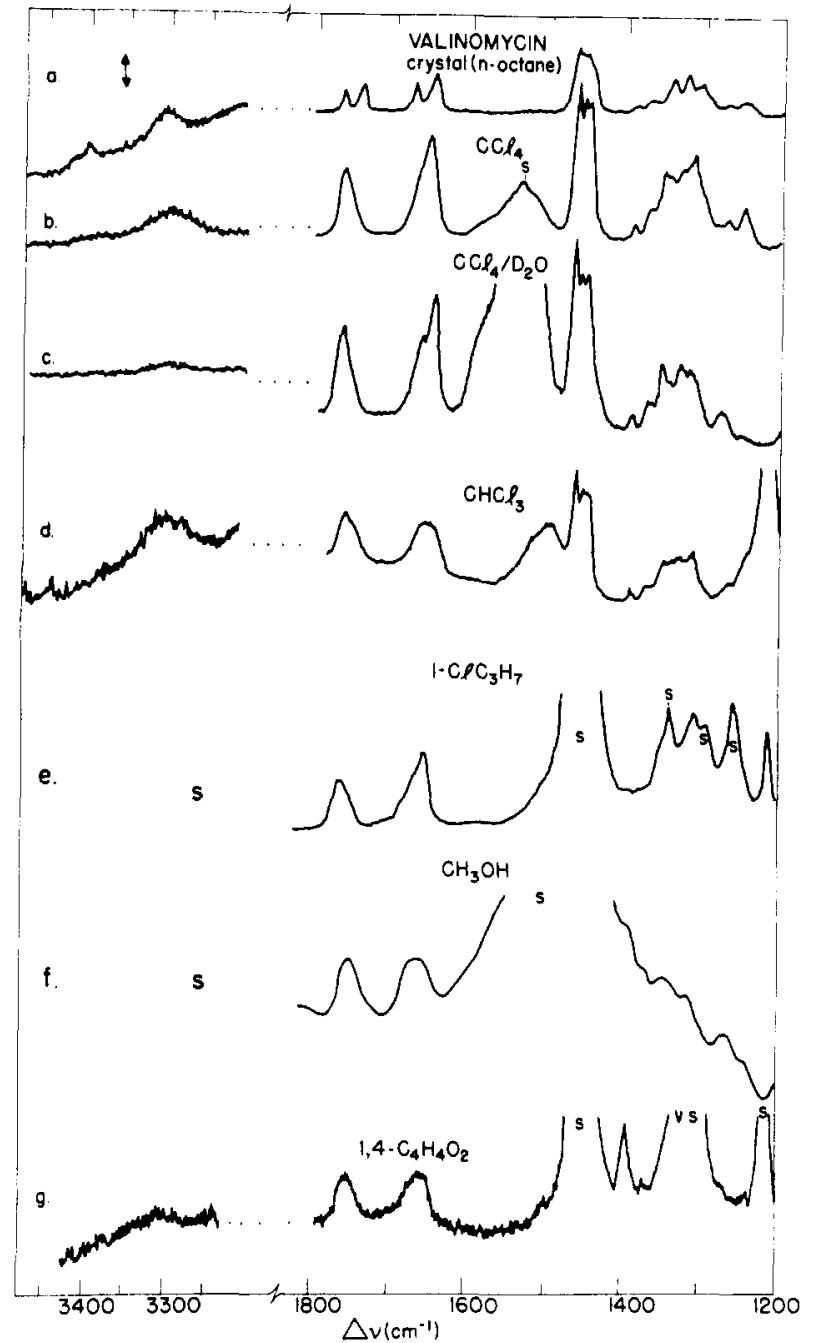

Figure 3. Continuation of Figure 2 to the $1200-1800$ and $3200-3500-\mathrm{cm}^{-1}$ regions.

$\mathrm{VM}-\mathrm{CCl}_{4}$ solution (Figure $4 \mathrm{~b}$ ) provides information on the extent of hydrogen bonding. For example, the frequency of the broad $1654-\mathrm{cm}^{-1}$ peak of $\mathrm{VM}-\mathrm{CCl}_{4}$ is near that of the narrower $1649-\mathrm{cm}^{-1}$ peak observed in the solid state (hydrogenbonded amide $\mathrm{C}=\mathrm{O}$ stretch). The $1675-\mathrm{cm}^{-1}$ amide $\mathrm{C}=\mathrm{O}$ peak of crystalline VM (free amide $C=0$ stretch) does not appear in $\mathrm{VM}-\mathrm{CCl}_{4}$, although the marked upward asymmetry of the amide $\mathrm{C}=\mathrm{O}$ band suggests that there still exist relatively "free" $\mathrm{C}=\mathrm{O}$ groups.

In the ester $\mathrm{C}=\mathrm{O}$ stretch region, $\mathrm{VM} / \mathrm{CCl}_{4}$ exhibits a broad asymmetric peak at $1760 \mathrm{~cm}^{-1}$ which is $7 \mathrm{~cm}^{-1}$ below the free ester $\mathrm{C}=\mathrm{O}$ stretch frequency of crystalline VM. The lowfrequency asymmetry may represent contributions from intramolecularly hydrogen-bonded ester $\mathrm{C}=\mathrm{O}$ groups (a characteristic feature of conformation $\mathrm{D}$ ), or from the presence of unbonded ester $\mathrm{C}=\mathrm{O}$ groups exposed in different degrees to the solvent. Carbonyl groups exposed to solvent interactions typically have a lower stretch frequency and larger peak width than unexposed $\mathrm{C}=\mathrm{O}$ groups; ${ }^{12}$ however, such interactions should be weak in $\mathrm{CCl}_{4}$ (a nonpolar solvent) compared to the effects of intramolecular VM hydrogen bonding.

One can further decompose the $\mathrm{C}==\mathrm{O}$ stretch bands of VM by using a polarization analyzer to separate scattered light with polarization perpendicular $(\perp)$ and parallel $(\|)$ to the scattering plane. The incident laser light is polarized $\perp$ to the scattering plane, so that Raman spectra taken with (incident, scattered) polarizations $(\perp, \|)$ will contain only "depolarized" peaks, lacking Raman scattering which retains its original polarization ("polarized" peaks).

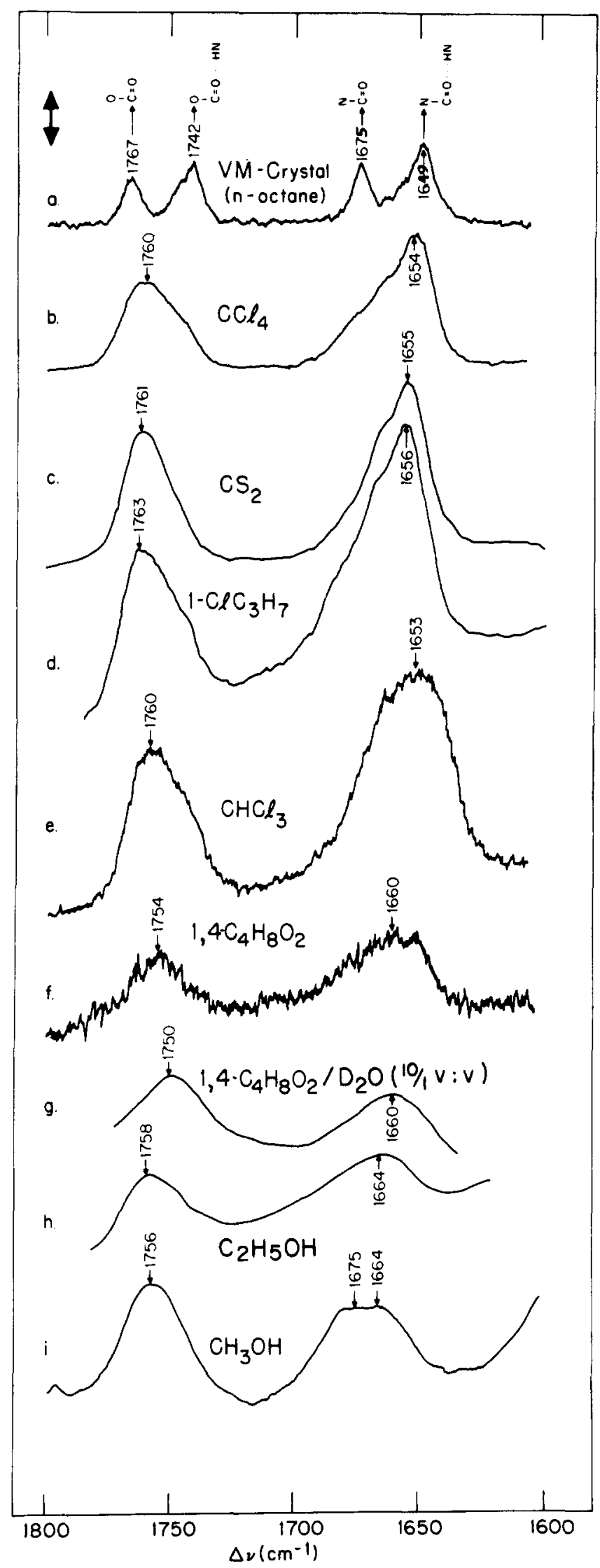

Figure 4. Comparison of Raman spectra in the $\mathrm{C}=\mathrm{O}$ stretch vibration region of: (a) VM grown from $n$-octane, and solutions of $\mathrm{VM}$ dissolved in (b) $\mathrm{CCl}_{4}$, (c) $\mathrm{CS}_{2}$, (d) $1-\mathrm{ClC}_{3} \mathrm{H}_{7}$, (e) $\mathrm{CHCl}_{3}$, (f) 1,4-dioxane, (g) 1,4-dioxane/ $\mathrm{D}_{2} \mathrm{O}(10: 1 \mathrm{v} / \mathrm{v})$, (h) $\mathrm{C}_{2} \mathrm{H}_{5} \mathrm{OH}$, (i) $\mathrm{CH}_{3} \mathrm{OH}$. Spectra were recorded with incident power $20-200 \mathrm{~mW}$, exciting frequency $457.9,488.0$, $514.5 \mathrm{~nm}$, spectral resolution $3 \mathrm{~cm}^{-1}$, scanning speed $0.1-0.5 \mathrm{~cm}^{-1} / \mathrm{s}$. Vertical arrow represents 300 counts $/ \mathrm{s}$. No analyzer in scattered beam, incident light polarized. $S$ denotes solvent peak. 
When decomposed in this manner, the ester $\mathrm{C}=0$ stretch region of VM-CCl 4 (Figure 5) consists of a symmetric depolarized $(\perp, \|)$ peak near $1755 \mathrm{~cm}^{-1}$ and a polarized $(\perp, \perp)$ peak at $1760 \mathrm{~cm}^{-1}$ with a distinct shoulder near $1745 \mathrm{~cm}^{-1}$. The frequency of the latter is close enough to the $1742 \mathrm{~cm}^{-1}$ hydrogen bonded $\mathrm{C}=\mathrm{O}$ stretch frequency of crystalline $\mathrm{VM}$ (Figure 4a) to suggest that some hydrogen-bonded $\mathrm{C}=\mathrm{O}$ groups may be present in $\mathrm{CCl}_{4}$ solution (as in conformation D).

The amide $\mathrm{C}=\mathrm{O}$ stretch region consists of a depolarized $(\perp, \|)$ band at $1667 \mathrm{~cm}^{-1}$ and a highly polarized $(\perp, \perp)$ band at $1650 \mathrm{~cm}^{-1}$ (Figure 5); the latter is near the frequency expected for hydrogen-bonded amide $\mathrm{C}=\mathrm{O}$ groups. The frequency of the $1667-\mathrm{cm}^{-1}$ band, while not as high as in crystalline VM $\left(1675 \mathrm{~cm}^{-1}\right)$, is nonetheless consistent with the presence of unbonded amide $C=O$ groups.

Substituting deuterium for hydrogen facilitates assignments of vibrations that involve $\mathrm{NH}$ groups. ${ }^{13}$ Since $\mathrm{D}_{2} \mathrm{O}$ does not mix with $\mathrm{CCl}_{4}$, a $\mathrm{D}_{2} \mathrm{O}$ phase is placed in contact with the $\mathrm{VM}-\mathrm{CCl}_{4}$ solution; after about $24 \mathrm{~h}$ deuterium exchange reaches completion as determined by Raman observations of the VM in the $\mathrm{CCl}_{4}$ phase. Upon deuteration, the amide I regions show a peak at $1645 \mathrm{~cm}^{-1}$ with a clear shoulder near $1660 \mathrm{~cm}^{-1}$. In contrast, the shoulder on the ester carbonyl vibration, which is most apparent in the $(\perp, \perp)$ spectrum, seems to disappear upon deuteration (cf. Figure 5).

(2) The Amide III Region. The amide III vibration consists primarily of $\mathrm{NH}$ bend and $\mathrm{C}=\mathrm{O}$ stretch of the peptide linkage. ${ }^{13}$ The frequency of this vibration varies between 1230 and $1330 \mathrm{~cm}^{-1}$ in most polypeptides and is sensitive to hydrogen bonding. ${ }^{14-20}$ Although several $\mathrm{C}-\mathrm{C}$ and $\mathrm{CH}$ vibrations also occur in this spectral region, the amide III vibrations can usually be identified by their sensitivity to conformational change and by their marked frequency shift upon deuteration of the NH group.

Deuteration of the NH group typically shifts amide III modes from the $1220-1330-\mathrm{cm}^{-1}$ region to the $850-950-\mathrm{cm}^{-1}$ region. ${ }^{21}$ The $1248-\mathrm{cm}^{-1}$ peak of $\mathrm{VM}-\mathrm{CCl}_{4}$ disappears upon deuteration (Figure $3 \mathrm{c}$ ), and a new peak appears near 920 $\mathrm{cm}^{-1}$. There is also a reduction of intensity near $1313 \mathrm{~cm}^{-1}$, which indicates that both peaks involve amide vibrations.

The $1307-\mathrm{cm}^{-1}$ peak of crystalline VM (Figure 3 ) is shifted to $1313 \mathrm{~cm}^{-1}$ in VM-CCl 4 solution, and its intensity increases (perhaps partially due to the upward shift of its low-frequency components). The $1252-\mathrm{cm}^{-1}$ peak of crystalline VM is shifted to $1248 \mathrm{~cm}^{-1}$ in $\mathrm{CCl}_{4}$ solution.

(3) The NH Stretch Region. Unbonded NH stretch vibrations are observed near $3312 \mathrm{~cm}^{-1}$ in crystalline VM; a single broad peak is observed near $3305 \mathrm{~cm}^{-1}$ in $\mathrm{CCl}_{4}$ solution (Figure $3 a, b)$. Upon deuteration this band is reduced in intensity (Figure 3d) and a new peak emerges near $2470 \mathrm{~cm}^{-1}$, as might be expected for an ND stretch mode.

(B) $\mathrm{CS}_{2}$ (Nonpolar) and $\mathrm{CHCl}_{3}$ (Weakly Polar) Solution. Like $\mathrm{CCl}_{4}, \mathrm{CS}_{2}$ has a zero dipole moment, and Raman spectra of $\mathrm{VM}$ in the two solvents are very similar. In particular, similar asymmetries appear in the amide and ester $\mathrm{C}=\mathrm{O}$ stretch bands. Shoulders near 1675 and $1745 \mathrm{~cm}^{-1}$ are apparent even in the unpolarized spectrum and again are more pronounced in the depolarized and polarized spectra.

$\mathrm{CHCl}_{3}$ has a small dipole moment $(D=1.02 \mathrm{D})$ with excess positive charge on the hydrogen atom; thus $\mathrm{CHCl}_{3}$ can interact with $\mathrm{VM} \mathrm{C}=\mathrm{O}$ groups. The Raman spectrum of $\mathrm{VM}-\mathrm{CHCl}_{3}$ (Figure 2d) is similar to that of VM-CCl 4 and $\mathrm{VM}-\mathrm{CS}_{2}$, although in this solvent the amide $\mathrm{C}=\mathrm{O}$ stretch band shifts to higher frequency and becomes broader and more symmetric. The ester $\mathrm{C}=\mathrm{O}$ stretch band remains unchanged (Figure 4e).

Dichloromethane $\left(\mathrm{CH}_{2} \mathrm{Cl}_{2}\right)$ has a larger dipole moment $(D$ $=1.54 \mathrm{D})$. The VM spectrum still appears similar to VM

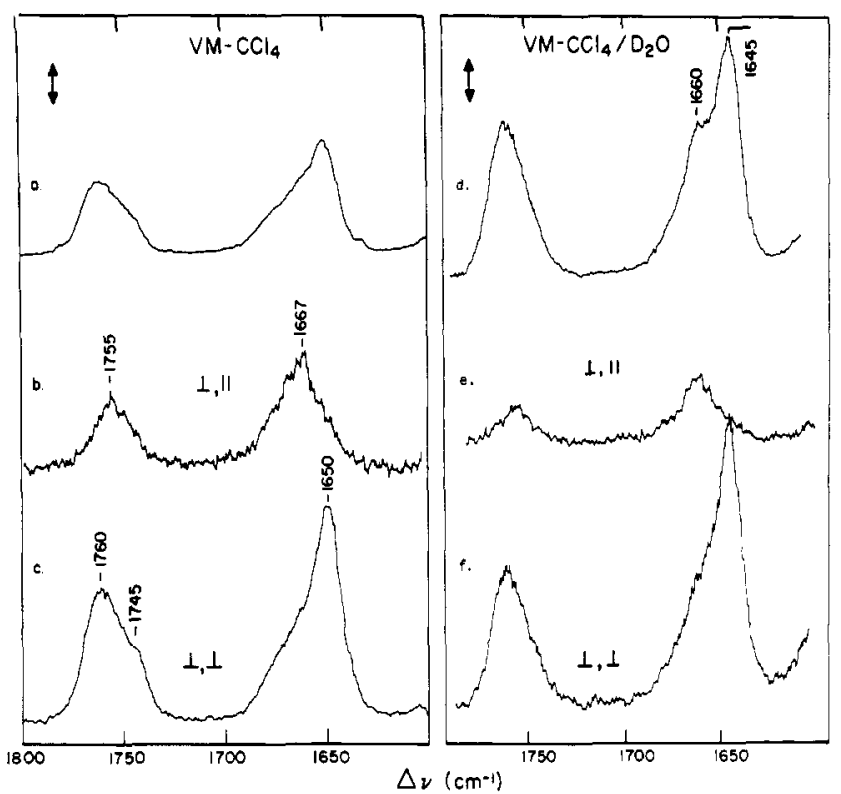

Figure 5. Raman spectra of valinomycin- $\mathrm{CCl}_{4}$ solution in the $1600-$ $1800-\mathrm{cm}^{-1}$ region recorded with (a) no analyzer in scattered beam, (b) analyzer parallel to scattering plane, and (c) analyzer perpendicular to scattering plane. Spectra a, b, c were recorded with incident power 150 $\mathrm{mW}$, exciting frequency $488.0 \mathrm{~nm}$, spectral resolution $3 \mathrm{~cm}^{-1}$, scanning speed $0.2 \mathrm{~cm}^{-1} / \mathrm{s}$. The vertical arrow represents 1000,100 , and 300 counts in $a, b$, and c, respectively. The spectra of parts (d)-(f) correspond to the spectra of parts (a)-(c) except that the samples are deuterated. Spectra (d, e, f) were recorded with incident power $200 \mathrm{~mW}$, exciting frequency $457.9 \mathrm{~nm}$, spectral resolution $3 \mathrm{~cm}^{-1}$, scanning speed $0.5 \mathrm{~cm}^{-1} / \mathrm{s}$. The vertical arrow represents 300 counts $/ \mathrm{s}$.

dissolved in nonpolar solvents, although the amide $\mathrm{C}=\mathrm{O}$ appears shifted to a higher frequency, $1656 \mathrm{~cm}^{-1}$, and the ester $\mathrm{C}=\mathrm{O}$ to a lower frequency, $1760 \mathrm{~cm}^{-1}$.

(C) $\mathrm{C}_{3} \mathrm{H}_{7} \mathrm{Cl}$ Solution (Polar). Although VM is not sufficiently soluble in nonpolar hydrocarbons such as propane to provide quality Raman spectra, it dissolves readily in the polar hydrocarbon 1-chloropropane $\left(\mathrm{C}_{3} \mathrm{H}_{7} \mathrm{Cl}\right)$. Interestingly, its spectrum in that solvent does not differ significantly from that of $\mathrm{VM}$ in $\mathrm{CCl}_{4}$ (Table I and Figure 6). In particular the amide $\mathrm{C}=\mathrm{O}$ region is unchanged (except for a $2 \mathrm{~cm}^{-1}$ upshift in frequency), suggesting that increasing the dipole moment of the solvent from $D=0$ to $2.0 \mathrm{D}$ is, by itself, not sufficient to significantly change the equilibrium of VM conformations. At all concentrations of $\mathrm{VM}$ between 0.02 and $0.50 \mathrm{M}$ a polarized $1745-\mathrm{cm}^{-1}$ contribution to the ester $\mathrm{C}=\mathrm{O}$ stretch band was evident (cf. Figure 7). (Measurements at concentrations below $0.01 \mathrm{M}$ were not possible because of decreasing signalto-noise ratio.)

(D) $\mathrm{CH}_{3} \mathrm{OH}$ and $\mathrm{C}_{2} \mathrm{H}_{5} \mathrm{OH}$ Solution (Polar and Hydrogen Bonding). Although ethanol has a smaller dipole moment ( $D$ $=1.69 \mathrm{D})$ than 1-chloropropane, it has a greater effect on the conformationally sensitive $\mathrm{C}=\mathrm{O}$ stretch band of VM (Figure 4). The amide I band is broadened and shifted upward in frequency to above $1660 \mathrm{~cm}^{-1}$, and a slight splitting can be discerned in the polarized $(\perp, \|)$ spectrum. A symmetric ester $\mathrm{C}=\mathrm{O}$ stretch peak is observed, slightly downshifted, near 1758 $\mathrm{cm}^{-1}$. Ethanol has little observable effect on the rest of the VM spectrum; the amide III region cannot be studied due to the presence of solvent peaks.

In methanol $(D=1.70 \mathrm{D})$ the amide and ester $\mathrm{C}=\mathrm{O}$ stretch bands appear near 1665 and $1756 \mathrm{~cm}^{-1}$, respectively. The broad amide I band appears to contain a second component at higher frequency, $\sim 1675 \mathrm{~cm}^{-1}$. The amide III region is observable in methanol (Figure $3 f$ ) and shows significant changes from the corresponding region in $\mathrm{CCl}_{4}$ (Figure $3 \mathrm{~b}$ ). The intensity of the $1250-\mathrm{cm}^{-1}$ peak is reduced, and there is increased 
Table I. Raman Spectral Peaks from Valinomycin Crystals and Valinomycin Solutions ${ }^{a}$

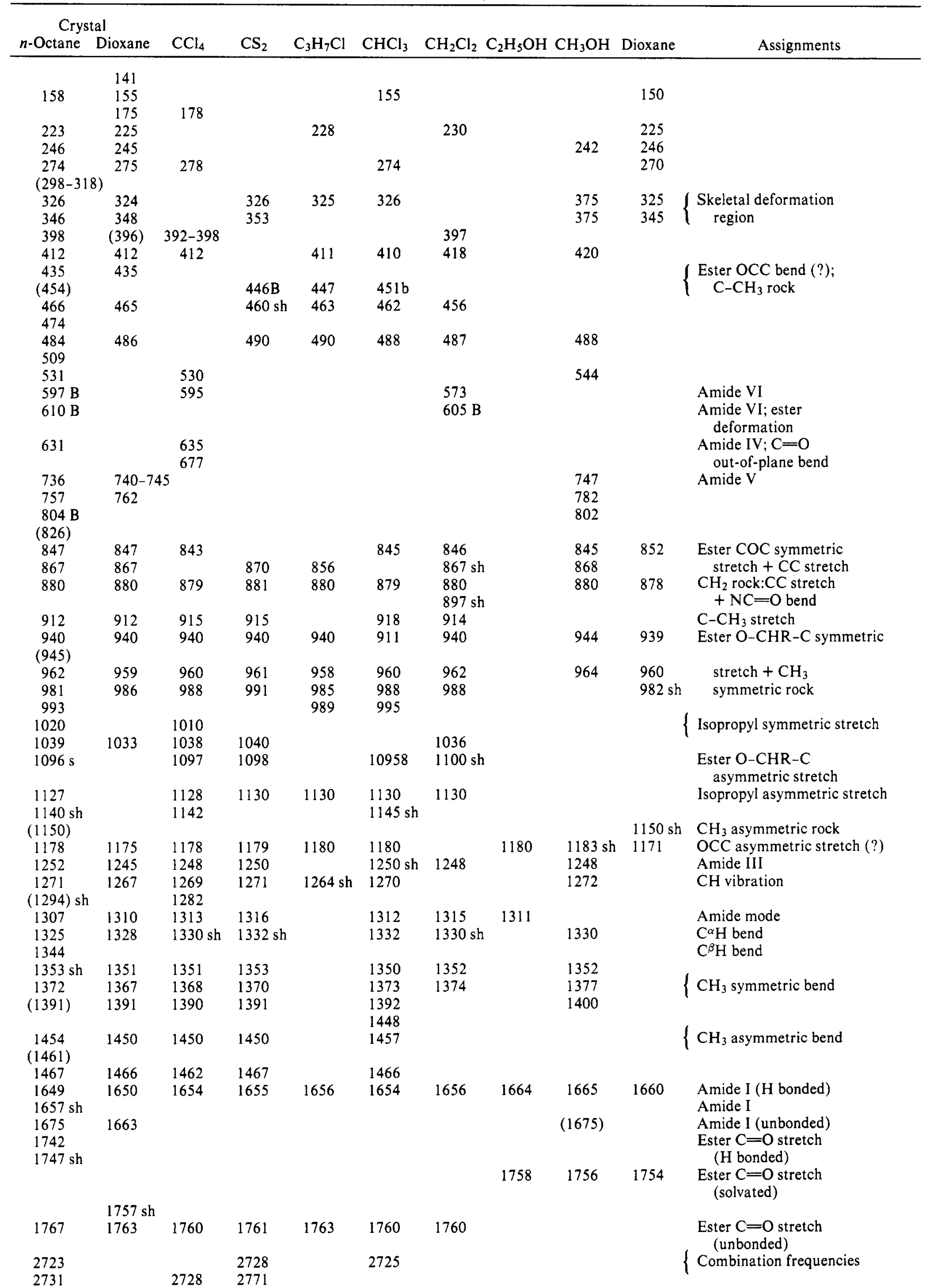


Table I (Continued)

\begin{tabular}{|c|c|c|c|c|c|c|c|c|c|c|}
\hline $\begin{array}{l}\text { Crys } \\
n \text {-Octane }\end{array}$ & Dioxane & $\mathrm{CCl}_{4}$ & $\mathrm{CS}_{2}$ & $\mathrm{C}_{3} \mathrm{H}_{7} \mathrm{Cl}$ & $\mathrm{CHCl}_{3}$ & $\mathrm{CH}_{2} \mathrm{Cl}_{2}$ & $\mathrm{C}_{2} \mathrm{H}_{5} \mathrm{OH}$ & $\mathrm{CH}_{3} \mathrm{OH}$ & Dioxane & Assignments \\
\hline $\begin{array}{c}(2765) \\
2774\end{array}$ & 2772 & 2770 & & & 2775 & & & & & \\
\hline 2875 & 2874 & $\begin{array}{l}2875 \\
2900 \text { sh }\end{array}$ & $\begin{array}{l}2874 \\
2900 \mathrm{sh}\end{array}$ & & $\begin{array}{l}2872 \\
2900 \mathrm{sh}\end{array}$ & & & & & Isopropyl $\mathrm{C}^{\beta} \mathrm{H}$ stretch \\
\hline 2913 & 2913 & 2912 & 2912 & 2930 & 2910 & & & & & $\mathrm{C}^{\alpha} \mathrm{H}$ stretch \\
\hline $\begin{array}{l}2938 \\
2966 \\
2984\end{array}$ & $\begin{array}{l}2936 \\
2972\end{array}$ & $\begin{array}{l}2940 \\
2967\end{array}$ & $\begin{array}{l}2940 \\
2970\end{array}$ & & $\begin{array}{l}2942 \\
2972\end{array}$ & & & & & $\begin{array}{l}\mathrm{CH}_{3} \text { symmetric stretch } \\
\mathrm{CH}_{3} \text { asymmetric stretch }\end{array}$ \\
\hline 3312 & $3301 \mathrm{~B}$ & 3305 & 3300 & 3304 & $\begin{array}{l}3305 \\
3390\end{array}$ & & & & & $\begin{array}{l}\text { NH stretch ( } \mathrm{H} \text { bonded) } \\
\text { NH stretch (unbonded) }\end{array}$ \\
\hline $\begin{array}{c}3406 \\
(3426)\end{array}$ & & & & & & & & & & \{Combination frequency \\
\hline
\end{tabular}

${ }^{a} \mathrm{~B}=$ broad, $\mathrm{sh}=$ shoulder, ? = uncertain assignment.

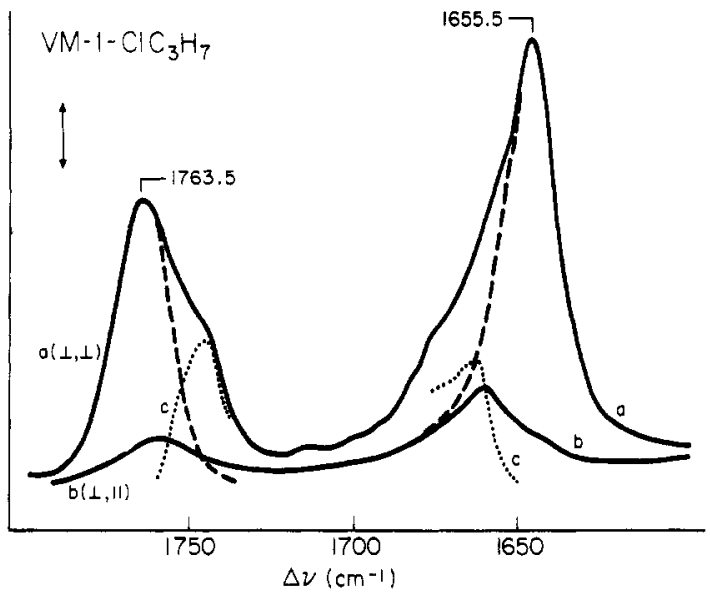

Figure 6. Raman spectra of $0.3 \mathrm{M}$ valinomycin-1- $\mathrm{ClC}_{3} \mathrm{H}_{7}$ (a) recorded with analyzer $\perp$ to scattering plane curve, (b) with analyzer $\|$ to scattering plane, (c) and with decomposition of a shoulder found by subtracting symmetric component (dashed line) from (a). Spectra recorded with incident power $200 \mathrm{~mW}$, exciting frequency $488.0 \mathrm{~nm}$, spectral resolution $3 \mathrm{~cm}^{-1}$, scanning speed $0.1 \mathrm{~cm}^{-1} / \mathrm{s}$. The vertical arrow represents 100 counts/s.

activity near $1275 \mathrm{~cm}^{-1}$. The $1313-\mathrm{cm}^{-1}$ peak totally disappears. There is also an increase in the intensity of the $868-\mathrm{cm}^{-1}$ peak relative to the $880-\mathrm{cm}^{-1}$ peak. Methanol has a similar effect on the 865 - and $800-\mathrm{cm}^{-1}$ peaks of the macrotetrolide nactins in which the $865-\mathrm{cm}^{-1}$ peak has been assigned to $\mathrm{C}-\mathrm{O}-\mathrm{C}$ symmetric stretch vibrations. ${ }^{22}$

(E) Dioxane and Dioxane $/ \mathrm{D}_{2} \mathrm{O}$ Solution (Nonpolar and Hydrogen Bonding). Dioxane is a hydrogen bond acceptor with zero dipole moment. Proton magnetic resonance studies ${ }^{9}$ of $\mathrm{VM}$ in $p$-dioxane and dioxane $/ \mathrm{D}_{2} \mathrm{O}$ indicate that in these hydrogen bonding environments VM has a significantly different conformation than in $\mathrm{CCl}_{4}$. The Raman spectrum of $\mathrm{VM}$ dissolved in pure dioxane and dioxane $/ \mathrm{D}_{2} \mathrm{O}$ (Figures. 2 and 3; Table I) confirms this conclusion. The broad amide $\mathrm{C}=\mathrm{O}$ band of VM-dioxane, centered near $1660 \mathrm{~cm}^{-1}$, is only slightly asymmetric; in $10: 1 \mathrm{v} / \mathrm{v}$ dioxane $/ \mathrm{D}_{2} \mathrm{O}$ it is symmetric and centered near $1662 \mathrm{~cm}^{-1}$. This band can be decomposed into a polarized $(\perp, \perp)$ component near $1655 \mathrm{~cm}^{-1}$ and a depolarized $(\perp, \|)$ component near $1665 \mathrm{~cm}^{-1}$. The ester $\mathrm{C}=\mathrm{O}$ stretch mode appears as a broad symmetric band centered near $1750 \mathrm{~cm}^{-1}$ in both dioxane and dioxane $/ \mathrm{D}_{2} \mathrm{O}$. In contrast the ester $\mathrm{C}=\mathrm{O}$ stretch frequency of $\mathrm{VM}$ recrystallized from dioxane $e^{5}$ is significantly higher.

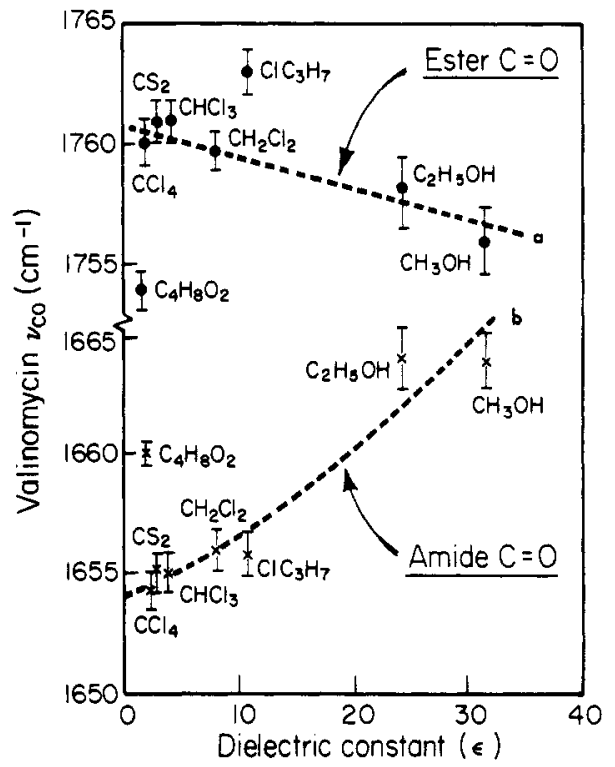

Figure 7. Plot of valinomycin amide $C=O$ and ester $C=0$ stretching frequencies as a function of the dielectric constant $\epsilon$ of the solvent. The dotted lines are only included to help visualize the general trend in the data and are not meant to imply any specific dependence of $\nu \mathrm{CO}$ on $\epsilon$ (such as a linear relationship).

The $100-400 \cdot \mathrm{cm}^{-1}$ region can be observed in dioxane solution. It resembles VM recrystallized from dioxane; ${ }^{5}$ for example, the $143-\mathrm{cm}^{-1}$ peak does not appear in spectra of VM recrystallized from $n$-octane. Vibrations in this region may represent hydrogen bond vibrations or delocalized, low-energy skeletal modes.

\section{Discussion}

(A) The $\mathrm{C}=\mathrm{O}$ Stretch Region. Nonpolar Solvents. Before reexamining the question of whether VM conformations other than conformations A (Figure 1c) or B (Figure 1d) exist in nonpolar solution, we will review the experiments through which the presence of those conformations were detected and their structures determined.

(1) Nuclear Magnetic Resonance. Measurements of the proton magnetic resonance temperature coefficient of VM in dioxane-octane ${ }^{9}$ suggest that all six nitrogen protons are solvent shielded and/or hydrogen bonded, whereas measurements in more polar solvents indicate a reduction in the number of such bonds. Although no splitting is seen in the chemical shifts of the nitrogen protons of $\mathrm{D}$ - and L-valine (implying threefold 
symmetry), this does not rule out the existence of rapidly exchanging conformers with lower symmetry (e.g., conformation D) since only an average of the chemical shifts of the nitrogen protons is observed. In fact, evidence for several rapidly exchanging conformers of $\mathrm{VM}$ in hexane $\left(T_{1}=2 \times 10^{-9} \mathrm{~s}, T_{2}\right.$ $=2 \times 10^{-8} \mathrm{~s}$ ) has been found ${ }^{10}$ using ultrasound absorption techniques.

(2) Infrared Spectroscopy. Infrared measurements of valinomycin in $\mathrm{CCl}_{4}$ and $\mathrm{CHCl}_{3}$ have led to the conclusion that both hydrogen bonded and free amide carbonyl groups are present. ${ }^{4,8} \mathrm{~A}$ high-frequency amide I shoulder is seen at 1678 $\mathrm{cm}^{-1}$ and the NH stretch peak is a doublet (3310 and 3390 $\mathrm{cm}^{-1}$ ). Such a result is consistent with the presence of both conformations A and B. The presence of conformation D could also account for the high-frequency shoulder at $1678 \mathrm{~cm}^{-1}$ but would not be expected to give rise to activity near the 3400 $\mathrm{cm}^{-1}$ if the latter represented free NH stretch. However, a peak appears near $3406 \mathrm{~cm}^{-1}$ in the Raman spectrum of VM powder in conformation D although no free NH groups are present. This band may represent a combination frequency. ${ }^{5}$

(3) Optical Rotatory Dispersion. Although optical rotatory dispersion measurements ${ }^{4,8}$ reveal the presence of at least two different conformations of uncomplexed VM in solution, they provide little information on their molecular structures.

(4) Minimum Free Energy Calculations. A recent minimum energy calculation ${ }^{9}$ based on conformation $D$ predicts weak ester $\mathrm{C}=\mathrm{O}$ hydrogen bonds which would tend to be unstable in solution. However, recent Raman measurements ${ }^{5}$ on conformation $D$ reveal equal hydrogen-bonding-induced downshifts $\left(25 \mathrm{~cm}^{-1}\right)$ in the $\mathrm{C}=\mathrm{O}$ stretch frequency for both ester and amide $\mathrm{C}=\mathrm{O}$ groups, implying similar bond strengths.

Since none of the above mentioned solution studies exclude the existence of the crystal conformation $D$, it is important to consider the Raman evidence. Raman spectra ${ }^{5}$ of crystalline VM in conformation D exhibit hydrogen-bonded ester $C=0$ peaks at $1742 \mathrm{~cm}^{-1}$ and nonbonded amide $\mathrm{C}=\mathrm{O}$ peaks at 1675 $\mathrm{cm}^{-1}$. We note the presence of a low-frequency component of the ester $\mathrm{C}=\mathrm{O}$ stretch band of $\mathrm{VM}$ in $\mathrm{CCl}_{4}, \mathrm{CS}_{2}, \mathrm{CHCl}_{3}$, and $\mathrm{C}_{3} \mathrm{H}_{7} \mathrm{Cl}$ solution near $1745 \mathrm{~cm}^{-1}$ and a component of the amide carbonyl stretch band near $1667 \mathrm{~cm}^{-1}$. Although the asymmetry of the amide $\mathrm{C}=\mathrm{O}$ stretch band can also be explained by the presence of conformation $B$ (which also contains free amide $C=O$ groups), the asymmetry of the ester $\mathrm{C}=\mathrm{O}$ stretch band cannot.

Strongly coupled $\mathrm{C}=\mathrm{O}$ groups sometimes exhibit two or more stretch vibrations, corresponding to normal modes of different symmetry. ${ }^{14}$ Although this could partially account from the splitting of the ester carbonyl stretch band in nonpolar solutions, the existence of conformation $D$ in such solutions is a possibility which must be seriously reconsidered.

(B) The $\mathbf{C}=\mathbf{0}$ Stretch Region. Polar and Hydrogen-Bonding Solvents. The $C=O$ stretch frequency is expected to be sensitive to changes which affect either intramolecular hydrogen bonding ${ }^{12}$ or interactions with the solvent. ${ }^{25}$ Since solvents of different polarity are known to alter the conformation of $\mathrm{VM},{ }^{4,8-10} \mathrm{VM}$ was studied in a variety of solvents $\left(\mathrm{CCl}_{4}, \mathrm{CS}_{2}\right.$, $\mathrm{CHCl}_{3}, \mathrm{CH}_{2} \mathrm{Cl}_{2}$, 1-chloropropane $\left(\mathrm{C}_{3} \mathrm{H}_{7} \mathrm{Cl}\right), \mathrm{C}_{2} \mathrm{H}_{5} \mathrm{OH}$, $\mathrm{CH}_{3} \mathrm{OH}$, $p$-dioxane $\left(\mathrm{C}_{4} \mathrm{H}_{8} \mathrm{O}_{2}\right)$, and $p$-dioxane $\left./ \mathrm{D}_{2} \mathrm{O}\right)$ with different dipole moments, dielectric constants, and hydrogen bonding capacities. Figures $7 \mathrm{a}$ and $7 \mathrm{~b}$ display the observed amide and ester $\mathrm{C}=\mathrm{O}$ stretch frequencies $\nu_{\mathrm{CO}}$ plotted as a function of dielectric constant $\epsilon$. It is found that the stretching frequency of the amide $\mathrm{C}=\mathrm{O}$ groups tends to increase with $\epsilon$, except for the cases of dioxane, $\mathrm{CH}_{3} \mathrm{OH}$, and $\mathrm{C}_{2} \mathrm{H}_{5} \mathrm{OH}$ (where a splitting occurs). In contrast, the stretching frequency of the ester $\mathrm{C}=\mathrm{O}$ groups decreases with increasing $\epsilon$, except for dioxane and 1 -chloropropane.

A decrease in $\mathrm{C}=\mathrm{O}$ stretch frequency with increasing dipole moment of the solvent has also been observed in model compounds. ${ }^{25,26}$ Recently, a study of $\nu_{\mathrm{CO}}$ vs. $\epsilon$ for a variety of model compounds was made. ${ }^{27}$ In the case of the model compound acetone dissolved in different solvents (at a solvent:acetone molar ratio of $8: 1$ ) the ester carbonyl stretch frequency decreases monotonically as a function of $\epsilon$ (except for $\left.\mathrm{C}_{3} \mathrm{H}_{7} \mathrm{Cl}\right)$. The similar behavior of the ester $\mathrm{C}=\mathrm{O}$ groups in VM may indicate that they are predominantly exposed to the solvent; this does not, however, rule out the possibility that a minority (e.g., 2 out of 6 ) of the ester $\mathrm{C}=\mathrm{O}$ groups are intramolecularly hydrogen bonded.

In contrast, the increase of $\nu_{\mathrm{CO}}$ with $\epsilon$ for the amide $\mathrm{C}=\mathrm{O}$ groups of VM indicates that the effect of the solvent on these groups differs from that on the exposed free $\mathrm{C}=\mathrm{O}$ groups in acetone. A similar increase was found for intermolecular hydrogen bonded model compounds such as $N$-methylacetamide. ${ }^{27}$ This supports the contention that most of the amide $\mathrm{C}=\mathrm{O}$ groups of $\mathrm{VM}$ are hydrogen bonded. The increase in solvent polarity (and its ability to form hydrogen bonds) may shift the conformational equilibrium of the system toward conformations with fewer intramolecularly bonded amide $\mathrm{C}=\mathrm{O}$ groups (e.g., conformation $\mathrm{B}$, Figure $1 \mathrm{~d}$ ) with a consequent rise in the average frequency of the amide $C=O$ stretch bond. A second possibility is that more polar solvents weaken the hydrogen bonds, thereby raising $\nu_{\mathrm{CO}}$. Raman spectroscopy alone cannot readily distinguish between these alternatives.

The anomalous effect of 1-chloropropane on the ester $\mathrm{C}=\mathrm{O}$ stretch frequency of VM (Figure 7) and acetone may be explained by the inability of 1-chloropropane to form hydrogen bonds. Nonetheless, 1-chloropropane may disrupt or weaken VM hydrogen bonds by interacting electrostatically with the NH groups. This may account for its "normal" position on the curve for $\mathrm{VM}$ amide $\mathrm{C}=\mathrm{O}$ groups in Figure 7. Dioxane, which disrupts hydrogen bonds due to its hydrogen bond accepting ability, also gives rise to an anomalously high VM amide $\nu_{\mathrm{CO}}$ and anomalously low ester $\nu_{\mathrm{CO}}$ (Figure 6).

In general, plots of $\nu_{\mathrm{CO}}$ vs. the dielectric constant $\epsilon$ may be an effective way to detect intramolecular hydrogen bonding. A decrease of $\nu_{\mathrm{CO}}$ with $\epsilon$ would indicate semifree $\mathrm{C}=0$ groups, while an increase in $\nu_{\mathrm{CO}}$ with $\epsilon$ would indicate hydrogenbonded $\mathrm{C}=\mathrm{O}$ groups. Further, comparisons with model compounds such as acetone may help provide information on the microenvironment of $\mathrm{C}=\mathrm{O}$ groups inside molecules like valinomycin. ${ }^{27}$

Deuteration of $\mathrm{VM}$ in $\mathrm{CCl}_{4}$ (by exchange with a $\mathrm{D}_{2} \mathrm{O}$ phase) results in several changes in the Raman spectrum (Figures 2, 3 , and 5). The observed change of shape of the amide $\mathrm{C}=\mathrm{O}$ stretch peak may arise from incomplete deuteration of the $\mathrm{NH}$ groups; this is supported by residual activity at 3320 (NH stretch) and $1250 \mathrm{~cm}^{-1}$ (amide III). The inability of those $\mathrm{NH}$ groups to exchange $\mathrm{H}$ for $\mathrm{D}$ may reflect strong hydrogen bonding. The shoulder at $1660 \mathrm{~cm}^{-1}$ could also arise from the presence of free amide $\mathrm{C}=\mathrm{O}$ groups whose stretch frequency $\nu_{\mathrm{CO}}$ is expected to be higher than that of hydrogen-bonded $\mathrm{C}=\mathrm{O}$ groups.

The reduction of the low-frequency shoulder of the ester carbonyl peak upon NH deuteration is more difficult to explain, unless one assumes that some of the ester $\mathrm{C}=0$ groups are hydrogen bonded (as in conformation D).

(C) The Amide III Region. The amide III vibration is known to be extremely sensitive to hydrogen bonding and the conformation of polypeptides. ${ }^{15-19}$ In model homopolypeptides, Chen and Lord ${ }^{20}$ locate the amide III modes of $\alpha$-helices near $1265-1300 \mathrm{~cm}^{-1}, \beta$ antiparallel-pleated sheets near $1229-1235$ $\mathrm{cm}^{-1}$ (with a second weaker band near $1289-1295 \mathrm{~cm}^{-1}$ ), and random coil structures near $1243-1253 \mathrm{~cm}^{-1}$. No corresponding empirical rules are available for depsipeptides like VM.

The amide III peaks of $\mathrm{VM}$ in $\mathrm{CCl}_{4}$ and in the solid state 
(conformation D) are similar, which suggests similarity in their conformations. In contrast, the amide III region of VM$\mathrm{CH}_{3} \mathrm{OH}$ is different. In particular, the disappearance of the high-frequency component of the amide III vibration may reflect the loss of hydrogen bonds in the more polar solvent.

Deuteration of VM in $\mathrm{CCl}_{4}$ solution (Figure 4) corroborates the assignment of the 1248- and $1313-\mathrm{cm}^{-1}$ peaks of $\mathrm{VM}-\mathrm{CCl}_{4}$ to amide III vibrations; these vibrations appear at 1252 and $1307 \mathrm{~cm}^{-1}$ in crystalline VM (conformation D). The upward shift of the $1307-\mathrm{cm}^{-1}$ peak to $1313 \mathrm{~cm}^{-1}$ may account for its apparent increase in intensity in solution, since it is superposed on a second peak between 1325 and $1330 \mathrm{~cm}^{-1}$. In $\mathrm{CH}_{3} \mathrm{OH}$ (Figure 3d) the intensity of the $1250-\mathrm{cm}^{-1}$ peak is reduced to roughly half that of the $1275-\mathrm{cm}^{-1}$ peak, and no amide III peak appears above $1300 \mathrm{~cm}^{-1}$.

\section{Conclusion}

This study has focussed on the effect of different solvents on the amide and ester $\mathrm{C}=\mathrm{O}$ stretch frequencies of valinomycin. Using the Raman spectrum of the solid-state conformation $D$ as a reference, tentative conclusions were drawn about the extent of hydrogen bonding of the amide and ester $\mathrm{C}=\mathrm{O}$ groups. We find evidence suggesting that hydrogenbonded ester $\mathrm{C}=\mathrm{O}$ groups may be present in VM dissolved in nonpolar solvents; this in turn may indicate that conformer $\mathrm{D}$ is among the conformers present.

Increasing the polarity of the solvent shifts the conformational equilibrium of VM to forms containing fewer hydrogen bonds; these results are consistent with findings using other techniques. ${ }^{8-11}$ A plot of $\nu_{\mathrm{CO}}$ vs. dielectric constant of the solvent reveals an increase in $\nu_{\mathrm{CO}}$ for amide $\mathrm{C}=\mathrm{O}$ groups and a decrease in $\nu_{\mathrm{CO}}$ for ester $\mathrm{C}=\mathrm{O}$ groups. This may reflect weakening or rupture of amide $\mathrm{C}=\mathrm{O}$ hydrogen bonds induced by polar or hydrogen bonding solvents and a concomitant increase in solvent interaction with ester $\mathrm{C}=\mathrm{O}$ groups.

Further Raman studies will be made of VM incorporated into bilayers, as has recently been done for the membrane protein opsin. 27

Acknowledgments. We acknowledge helpful discussions with Drs. R. C. Lord, W. L. Duax, B. C. Pressman, G. Phillies, B. Tokar, and R. Sanches. This work was supported by an NEI
Fellowship to one of the authors (K.J.R.), the Research Corporation, and an NIH Biomedical Sciences Support Grant (NIH-5-S05-RR07047-08).

\section{References and Notes}

(1) (a) Department of Physiology, Boston University School of Medicine, and Department of Physics, Boston University, Boston, Mass. 02215; (b) Otfice of Science, U.S. Food and Drug Administration, Rockville, Md. 20852; (c) Department of Physics, National Technical University of Athens, Athens 147, Greece.

(2) B. C. Pressman, Neurosci. Res. Program, Bull., 9, 320 (1971).

(3) P. Mueller and D. O. Rudin, Biochem. Biophys. Res. Commun., 26, 398 (1967).

(4) Yu. A. Ovchinnikov, V. T. Ivanov, and A. M. Shkrob, "Membrane-Active Complexones"', Elsevier, New York, N.Y., 1974.

(5) I. M. Asher, K. J. Rothschild, E. Anastassakis, and H. E. Stanley, J. Am. Chem. Soc., preceding paper in this issue; K. J. Rothschild, I. M. Asher, E. Anastassakis, and H. E. Stanley, Science, 182, 384 (1973); I. M. Asher, K. J. Rothschild, and H. E. Stanley, J. Mol. Biol., 89, 205 (1974).

(6) W. L. Duax, H. Hauptman, C. M. Weeks, and D. A. Norton, Science, 176, 911 (1972); G. D. Smith, W. L. Duax, D. A. Langs, G. T. DeTitta, J. W. Edmonds, D. C. Rohrer, and C. M. Weeks, J. Am. Chem. SoC., 97, 7242 (1975).

(7) I. L. Karle, J. Am. Chem. Soc., 97, 4379 (1975)

(8) M. M. Shemyakin, Yu. A. Ovchinnikov, V. T. Ivanov, V. K. Antonov, E. I. Vinogradova, A. M. Shkrob, G. G. Malenkov, A. V. Evstratov, I. A. Laine, E. I. Melnik, and I. D. Ryabova., J. Membr. Biol., 1, 402 (1969).

(9) D. J. Patel and A. E. Tonelli, Biochemistry, 12, 486 (1973).

(10) E. Grell and T. Funck, J. Supramol. Struct., 1, 307 (1973).

(11) D. H. Haynes, A. Kowalsky, and B. C. Pressman, J. Biol. Chem., 244, 502 (1969).

(12) R. E. Richards and H. Thompson, J. Chem. Soc., 1248 (1947).

(13) T. Miyazawa, J. Shimanouchi, and S. Mizushima, J. Chem. Phys., 29, 611 (1958).

(14) J. L. Koenig, J. Polym. Sci., Part D, 60, 59 (1972).

(15) J. L. Koenig and P. L. Sutton, Biopolymers, 10, 89 (1971).

(16) R. C. Lord, Proc. Int. Congr. Pure Appl. Chem., 23, 7, 179 (1971)

(17) R. C. Lord and N. T. Yu., J. Mol. Biol, 51, 203 (1970).

(18) N. T. Yu and C. S. Liu, J. Am. Chem. Soc., 94, 5127 (1972)

(19) N. T. Yu, C. S. Liu, and D. C. O'Shea, J. Mol. Biol., 70, 117 (1972).

(20) M. C. Chen and R. C. Lord, J. Am. Chem. Soc., 96, 4760 (1974).

(21) M. C. Tobin, "Laser Raman Spectroscopy", Wiley, New York, N.Y., 1971.

(22) G. D. J. Phillies, I. M. Asher, and H. E. Stanley, Biopolymers, 14, 2311 (1975); Science, 188, 1027 (1975); I. M. Asher, G. D. J. Phillies, B. J. Kim, and H. E. Stanley ibid., 16, 157 (1977).

(23) M. Smith, A. G. Walton, and J. L. Koenig. Biopolymers, 8, 29 (1969).

(24) S. K. Freeman, "Applications of Laser Raman Spectroscopy", Wiley, New York, N.Y., 1974.

(25) H. Loato and P. Isolato, Acta Chem. Scand., 21, 2119 (1967)

(26) R. F. Kagorise and K. B. Whetrel, Spectrochim. Acta, 18, $341(1962)$.

(27) K. J. Rothschild, R. Sanches, and H. E. Stanley, manuscript in preparation.

(28) W. Weltner, J. Am. Chem. Soc., 77, 3941 (1955)

(29) K. J. Rothschild, J. R. Andrew, Wm. deGrip, and H. E. Stanley, Science, $1911176(1976)$.

\title{
Environmental Effects on Vibronic Band Intensities in Pyrene Monomer Fluorescence and Their Application in Studies of Micellar Systems
}

\author{
K. Kalyanasundaram and J. K. Thomas* \\ Contribution from the Department of Chemistry and Radiation Laboratory, ${ }^{1}$ \\ University of Notre Dame, Notre Dame, Indiana 46556. Received July 2, 1976
}

\begin{abstract}
The fluorescence intensities for various vibronic fine structures in the pyrene monomer fluorescence show strong solvent dependence. In the presence of polar solvents, there is a significant enhancement in the intensity of the $0-0$ vibronic band at the expense of other bands. This strong perturbation in the vibronic band intensities is more dependent on the solvent dipole moment than on the bulk solvent dielectric constant. This suggests the operation of some specific solute-solvent dipole-dipole interaction mechanism. The strong perturbation of the vibronic band intensities has been used as a probe to accurately determine critical micelle concentrations and also to investigate the extent of water penetration in micellar systems.
\end{abstract}

Fluorescence probe analysis is becoming an important area in biophysical studies of multimolecular aggregates such as micelles ${ }^{2}$ and membranes. ${ }^{3}$ Studies with pyrene as a fluo- rescence probe have received special consideration. 4,5 Pyrene has several interesting photophysical properties which make it suitable for use as an effective probe, notably the long life- 